\title{
Subclinical hypercortisolism: a state, a syndrome, or a disease?
}

\section{Guido Di Dalmazi, Renato Pasquali ${ }^{1}$, Felix Beuschlein and Martin Reincke}

Medizinische Klinik und Poliklinik IV, Klinikum der Universität München, Ziemssenstrasse 1, D-80336 München, Germany and ${ }^{1}$ Endocrinology Unit, Department of Medical and Surgical Sciences, S. Orsola-Malpighi Hospital, Alma Mater University of Bologna, 40138 Bologna, Italy

Correspondence should be addressed to G Di Dalmazi Email

Guido.Di_Dalmazi@med. uni-muenchen.de

\section{Abstract}

Subclinical hypercortisolism (SH), defined as alterations of the hypothalamus-pituitary-adrenal axis in the absence of clinical signs or symptoms related to cortisol secretion, is a common finding in patients with adrenal incidentalomas. The clinical correlates of this pathological condition have become clearer over the last few years. The aim of this review is to summarize the co-morbidities and the clinical outcomes of patients with $\mathrm{SH}$. According to the analysis of the results of the studies published within the last 15 years, hypertension and type 2 diabetes are a common finding in patients with $\mathrm{SH}$, occurring roughly in $2 / 3$ and $1 / 3$ of the patients respectively. Moreover, several additional cardiovascular and metabolic complications, like endothelial damage, increased visceral fat accumulation and impaired lipid metabolism have been shown to increase the cardiovascular risk of those patients. Accordingly, recent independent reports investigating the natural history of the disease in a long-term follow-up setting have shown that patients with $\mathrm{SH}$ have a higher incidence of cardiovascular events and related mortality. Moreover, longitudinal studies have also shown increased incidence of osteoporotic vertebral fractures. Future research is needed to improve the diagnostic performance of hormonal tests, by assessment of the complete steroid profile with more accurate assays, and to define the efficacy of surgical vs medical treatment in a randomizedcontrolled setting.

\section{Introduction}

The term 'adrenal incidentaloma' was coined to identify a group of adrenal masses that are incidentally discovered during imaging techniques performed for disorders unrelated to the adrenal gland. Despite the majority of those tumors are benign and not associated with clinically-relevant hormonal hyperfunction (namely cortisol, aldosterone, and catecholamines), an increasing number of patients with mild alteration of cortisol secretion without phenotype of Cushing's syndrome has been identified over the last decades. In an attempt to classify this subset of patients in a homogeneous group, the terms 'subclinical (or pre-clinical) Cushing's syndrome', 'subclinical autonomous glucocorticoid hypersecretion' and 'subclinical hypercortisolism (SH)' has been variably used

Invited Author's profile

Dr G Di Dalmazi is currently a researcher at Medizinische Klinik und Poliklinik IV, Ludwig Maximilian University, Munich, Germany. Since 2011, his research has focused on benign adrenocortical tumors associated with hypercortisolism. Recently, his research activity has included the study of cardiovascular impact and long-term co-morbidities of prolonged subtle cortisol exposure in adrenal incidentalomas. A parallel line of research developed during the last few months focuses on the analysis of the molecular mechanisms underlying tumor formation and cortisol hypersecretion in benign and malignant adrenocortical tumors.

(C) 2015 European Society of Endocrinology Printed in Great Britain Published by Bioscientifica Ltd.
This article is adapted from work presented at IMPROCUSH-1, 12-14 October 2014. The meeting was supported by the European Science Foundation, Deutsche

Forschungsgemeinschaft, Carl Friedrich von Siemens Stiftung, European Neuroendo-

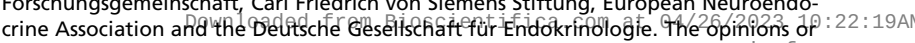
views expressed in this article are those of the authors, and do not necessarily reflecte access

the opinions or recommendations of the supporters of the symposium. 
in several publications. The term ' $\mathrm{SH}$ ' will be followed in this review because it is widely used in the most recent literature and it is the most appropriate description in our opinion. SH is becoming a very common finding in patients with adrenal incidentalomas $(1,2)$ and it recently has been a matter of intensive research. However, no clear and homogeneous indications for the diagnosis of these patients are available, leading to difficulty in the definition of a clinical phenotype and uncertainty in the appropriate post-diagnostic procedures (management and follow-up).

The aim of this review is to summarize the published evidence on co-morbidities and clinically relevant outcomes associated with $\mathrm{SH}$, in order to depict a clinical picture of patients affected by this condition.

\section{Remarks on diagnosis}

An extensive review on the diagnosis of $\mathrm{SH}$ has already been published in recent years (3) and is beyond the scope of this review. However, considering that diagnosis is a central aspect when dealing with $\mathrm{SH}$, some important remarks regarding radiological, clinical and hormonal characteristics of this pathological condition will be discussed below.

The classical triad commonly used to define $\mathrm{SH}$ is characterized by the presence of alterations of the hypothalamus-pituitary-adrenal axis in patients with incidentally discovered adrenal masses who do not exhibit signs and symptoms specific of overt Cushing's syndrome. This apparently simple definition carries several drawbacks that must be dealt with by physicians who face an increasing number of patients diagnosed with adrenal incidentalomas.

\section{Radiological evaluation}

By definition, adrenal incidentalomas are diagnosed with an imaging technique, such as ultrasonography, computerized tomography (CT), or magnetic resonance imaging, performed for reasons unrelated to adrenal diseases. Although imaging techniques are extremely helpful in the definition of the nature of adrenal incidentalomas $(4,5,6)$, there is not enough evidence that they can be used to characterize the functional status of the adenomas. In fact, only one study recently published by Olsen et al. (7) tried to investigate this possibility. In their cohort of 146 patients with complete hormonal evaluation, SH was defined using a combination of cortisol values after dexamethasone suppression test (DST) above $1.8 \mu \mathrm{g} / \mathrm{dl}$ and basal adrenocorticotrophin (ACTH) levels below
$10 \mathrm{pg} / \mathrm{ml}$. The group of unilateral adrenal masses with size over $2.5 \mathrm{~cm}$ and CT attenuation below 1 showed a $45 \%$ prevalence of $\mathrm{SH}$. Coherently, the probability of having $\mathrm{SH}$ correlated positively with the size and negatively with the density of the adrenal mass. Although this study carries several limitations due to its multicentric design and incomplete hormonal data in around $1 / 3$ of the patients, it highlights that the radiological characteristics can be useful in distinguish the nature, as already known, but also the functional status of the adrenal mass.

However, even if the radiological definition of the adrenal incidentalomas has become clearer in recent years due to the development of highly advanced techniques including functional imaging and to the increasing skill of radiologists (who are chiefly dedicated to endocrine diseases in some centers), no single or combined radiological parameters can be helpful in assessing the functional status of the adrenal mass.

\section{Clinical evaluation}

The first difficulty in the diagnosis of $\mathrm{SH}$ has to do with the recognition of the phenotypical aspect of the patients. By definition, physicians should suspect this condition in patients without typical signs and symptoms of Cushing's syndrome. However, it is well known from daily clinical practice that recognition of Cushing's syndrome and its differential diagnosis with obesity, especially the sarcopenic phenotype (8), can be extremely challenging. This aspect has been beautifully highlighted by Schneider et al. (9) in 2012, showing that the clinical picture of Cushing's syndrome has changed during the last 20 years, mainly because of the increasing knowledge among physicians about the clinical phenotype of hypercortisolism, which allows early recognition of the disease. It must be pointed out that the increasing ability to recognize patients with Cushing's syndrome could vary greatly among different centers, especially considering that there are some centers more prone than others to assist patients with adrenal diseases.

In this context, it must be emphasized that the absence of clinical signs and symptoms related to cortisol hypersecretion, which is the first rate-limiting step in the definition of $\mathrm{SH}$, is a very weak diagnostic criterion because it relies entirely on the clinical evaluation of single physicians and therefore on their personal experience. However, as discussed later in this review, evidence from recent studies highlights the fact that associated clinical biomarkers (e.g., increased visceral fat accumulation) and specific co-morbidities can contribute to define a characteristic clinical picture in patients with SH. 


\section{Hormonal evaluation}

Hormonal parameters to define $\mathrm{SH}$ are an additional source of uncertainty. To date, there are five clinical practice guidelines available $(10,11,12,13,14)$, which have been critically reviewed by Shen et al. (15) in 2014. In their quality assessment, the authors revealed that the guidelines of the Endocrine Society and those of the Italian Association of Medical Endocrinologists (AME) are the most recommendable among the others, albeit with modifications, according to the criteria of the Appraisal of Guidelines Research and Evaluation (AGREE-II) and those of the Institute Of Medicine (IOM) (15). All published guidelines agree with the use of $1 \mathrm{mg}$ DST for the screening of hypercortisolism. However, there is disagreement on the best cut-off for cortisol after DST, since values of $1.8 \mu \mathrm{g} / \mathrm{dl}$ as well as $5.0 \mu \mathrm{g} / \mathrm{dl}$ are recommended as limits for normal cortisol suppression. The landscape of the different cut-offs for cortisol after DST is even more complex when taking into account that an intermediate cut-point of $3.0 \mu \mathrm{g} / \mathrm{dl}$ has also been proposed by some authors after validation made on a clinical basis (16). However, it must be pointed out that there is a lack of proper control groups in defining the optimal cut-off for cortisol suppression. Indeed, a study published by Piaditis et al. (17) revealed that the optimal cut-off for cortisol after low-dose DST, calculated as mean \pm 2 s.D. values obtained from 72 control subjects without adrenal masses at high-resolution CT scan, could be even lower than $50 \mathrm{nmol} / \mathrm{l}$, as it was set to $30.1 \mathrm{nmol} / \mathrm{l}$. In addition, several different complementary criteria have been proposed by the guidelines as adjunctive diagnostic test in order to improve the sensitivity and the specificity in the detection of SH. The accuracy of the most frequently used hormonal tests has been already assessed in a comprehensive review published by Chiodini (3) in 2011. According to the results of this analysis, it is clear that the main source of variability in sensitivity and specificity relies on the outcomes that were used to calculate those two parameters. Overall, ACTH and urinary free cortisol (UFC) did not show satisfactory sensitivity and specificity in detecting $\mathrm{SH}$, whereas the altered circadian rhythm of cortisol, measured by increased midnight cortisol either in saliva or in serum, showed a reasonable accuracy (sensitivity 64\%, specificity $81 \%$ ) in predicting post-surgical hypocortisolism (considered as an indirect index of adrenal autonomy). An even higher variability in sensitivity and specificity was observed for cortisol after DST, when different cut-offs were set (3). It is clear that the lowest cut-off $(1.8 \mu \mathrm{g} / \mathrm{dl})$ leads to high sensitivity, which, in turn, decreases with the highest cut-off point $(5 \mu \mathrm{g} / \mathrm{dl})$. The opposite trend is observed for specificity, as expected. In order to overcome this problem, the AME has proposed the use of a double cut-off for cortisol (1.8 and $5 \mu \mathrm{g} / \mathrm{dl}$ ) (14) that could be indeed a good compromise to achieve the highest diagnostic performance of the DST. In this view, hormonal tests with lower predictive accuracy (ACTH, UFC, or midnight cortisol) can be used as additional tests in cases of intermediate values of cortisol after DST (between 1.8 and $5 \mu \mathrm{g} / \mathrm{dl}$ ). Overall, the DST is the most reliable test to separate patients in different groups according to the severity of hypercortisolism, providing useful information to define patients at high risk of developing severe outcomes (as discussed in the next sections of this review).

However, the diagnostic flow-chart of SH is highly challenging and clear standards are still lacking. The most obvious consequence of this uncertainty is the nonhomogeneous classification of the patients among different centers that invariably lead to non-reproducible results in the analysis of clinical correlates. Therefore, the diagnostic criteria used to define patients with $\mathrm{SH}$ must be always taken into account when interpreting the results of studies that could affect the management of these patients in clinical practice. Future research is needed to assess the response of cortisol after DST, together with a daily rhythm of salivary cortisol, in a large cohort of normal subjects without proven morphological alterations in the adrenal glands, in order to create standardized cut-offs and definitively lower the variability among studies.

\section{Overview of associated co-morbidities}

It is a well-established concept that hypercortisolism can lead to associated co-morbidities, including metabolic and cardiovascular disturbances, as known from patients with overt Cushing's syndrome. SH has been associated with several metabolic and cardiovascular co-morbidities (18), even if there are contrasting results in the literature published up to now. However, the most common metabolic and cardiovascular correlates reported in patients with this condition are hypertension and impairment of glucose metabolism, mainly type 2 diabetes (T2D), which will be briefly discussed below. Table 1 shows an overview of the studies published in the last 15 years with data on prevalence of hypertension and T2D in cohorts with at least ten patients with SH. Accurate calculation of the total mean prevalence of hypertensive and diabetic patients among studies would lead to nonrealistic results, due to an overlap between several cohorts of patients, which are difficult to identify. 
Table 1 Overview of the studies published over the last 15 years reporting prevalence of hypertension and type 2 diabetes, in series of at least ten patients with subclinical hypercortisolism.

\begin{tabular}{|c|c|c|c|c|c|c|}
\hline \multirow[b]{2}{*}{ References } & \multirow[b]{2}{*}{ Total cohort $(n)$} & \multirow[b]{2}{*}{ Patients with SH (n) } & \multicolumn{2}{|c|}{ Hypertension (\%) } & \multicolumn{2}{|c|}{ Type 2 diabetes (\%) } \\
\hline & & & $\mathrm{SH}$ & NF/controls & $\mathrm{SH}$ & NF/controls \\
\hline (51) & 50 & 12 & 92 & - & 42 & - \\
\hline (1) & 1004 & 92 & 41 & $-^{a}$ & 8 & $-^{a}$ \\
\hline (44) & 126 & 28 & 61 & - & 36 & - \\
\hline (52) & 167 & 23 & 35 & 53 & 14 & 26 \\
\hline (53) & 11 & 11 & 63 & - & 36 & - \\
\hline (54) & 103 & 22 & 50 & 58 & 27 & 16 \\
\hline (55) & 45 & 45 & 73 & - & 31 & - \\
\hline (56) & 77 & 20 & 75 & 56 & 20 & 23 \\
\hline (57) & 108 & 41 & 59 & 57 & 27 & 9 \\
\hline (58) & 118 & 16 & 81 & 58 & 19 & 15 \\
\hline (59) & 60 & 29 & 48 & 61 & 35 & 13 \\
\hline (60) & 63 & 63 & 79 & - & 16 & - \\
\hline (61) & 16 & 16 & 56 & - & 25 & - \\
\hline (36) & 348 & $145^{b}$ & 82 & 73 & 27 & 15 \\
\hline (62) & 35 & 35 & 77 & - & $46^{c}$ & - \\
\hline (7) & 146 & 40 & 83 & 65 & $11^{d}$ & $8^{d}$ \\
\hline (63) & 213 & 51 & 65 & 55 & 26 & 24 \\
\hline (64) & 29 & 29 & 57 & - & 41 & - \\
\hline (65) & 70 & 16 & 69 & 59 & $69^{c}$ & $32^{c}$ \\
\hline (66) & 298 & 66 & 71 & 61 & 27 & 21 \\
\hline (46) & 206 & 39 & 67 & 54 & 33 & 17 \\
\hline (45) & 198 & 69 & 65 & 57 & 30 & 14 \\
\hline (47) & 206 & 111 & $64^{e}$ & $58^{e}$ & $24^{d}$ & $21^{d}$ \\
\hline (67) & 27 & 27 & 59 & - & 37 & - \\
\hline (68) & 237 & 19 & 78 & 55 & 42 & 29 \\
\hline (69) & 33 & 33 & 73 & - & - & - \\
\hline (29) & 330 & 93 & 74 & 62 & $41^{c}$ & $31^{c}$ \\
\hline
\end{tabular}

$\mathrm{SH}$, subclinical hypercortisolism; NF, non-functioning adrenal masses.

${ }^{a}$ Exact prevalence not reported, but not different respect to that of non-secreting adenomas $(n=854)$.

${ }^{\mathrm{b}} \mathrm{A}$ total of $19 \mathrm{SH}$ patients (cortisol after dexamethasone suppression test above $5 \mu \mathrm{g} / \mathrm{dl}$ ) and 126 patients with intermediate phenotype (cortisol after dexamethasone suppression test between 1.8 and $5 \mu \mathrm{g} / \mathrm{dl})$.

'Including impaired glucose tolerance.

dPercentage of patients on hypertensive treatment.

epercentage of patients on antidiabetic treatment.

Hypertension is one of the most common clinical features of patients with SH. The link between hypercortisolism and hypertension is well known in patients with endogenous and iatrogenic Cushing's syndrome, despite the exact mechanisms of the glucocorticoid-induced hypertension being still under investigation. Hypertension in Cushing's syndrome could be explained by a concurrence of several events, such as an impaired imbalance between vasodilators and vasoconstrictors (e.g., nitric oxide, prostacyclin, and endothelin-1) and activation of the mineralocorticoid receptor $(19,20,21$, $22,22)$. Moreover, several endothelial abnormalities and left ventricular dysfunctions have also been recorded $(21,22)$, indirectly confirming that the degree of hypertension in those patients could be indeed severe. The involvement of cortisol has been indirectly demonstrated by the positive effects of adrenalectomy on the cardiovascular profile of patients with SH. In a very recent systematic review of the literature published over the last 33 years, Iacobone et al. (23) showed that the surgical treatment appears to be more beneficial than medical therapy in achieving a cure or improvement of hypertension. Despite not being completely understood, the link between $\mathrm{SH}$ and hypertension can rely on direct effects of cortisol on the vascular system, as well as on indirect mechanisms, through impairment of glucose metabolism and increased waist circumference (as discussed below).

$\mathrm{SH}$ has been associated with impaired glucose metabolism, ranging from insulin resistance to T2D. Two recent reports showed increasing degrees of alterations of indices of insulin resistance in controls, patients with nonfunctioning adrenal adenomas and $\mathrm{SH}(24,25)$. T2D occurs in roughly one third of patients with SH. However, as expected, there is a high variability between studies, with prevalence of T2D that range from 5\% to 69\%, which could be explained by several factors, such as the different 
diagnostic criteria to define $\mathrm{SH}$, the change in diagnosis of T2D over a 15-year time span and the numerosity of the samples in different studies. A pathogenetic role of cortisol in the development of impairment glucose metabolism is easy to assume, considering the well-known effects of glucocorticoids on gluconeogenesis, insulin-dependent uptake in peripheral tissues and secretory activity of pancreatic $\beta$-cells (26). However, subclinical cortisol hyperproduction can also lead to T2D through indirect mechanisms. It has been recently shown by Debono et al. (27) that patients with SH have a significantly higher visceral fat accumulation than patients with non-secreting adrenal masses, as measured by CT-scan. Interestingly, the increased visceral fat was not different from that of patients with Cushing's syndrome. Moreover, recent studies have also pointed out that patients with $\mathrm{SH}$ have a high prevalence of nonalcoholic fatty liver disease and lipid metabolism alterations, which are independently associated with cortisol secretion $(28,29)$.

The presence of impaired glucose metabolism, visceral fat accumulation and lipid abnormalities concur to the dysmetabolic frame that is common in patients with SH. The involvement of cortisol in the development of metabolic abnormalities in $\mathrm{SH}$ has been indirectly demonstrated by studies investigating the concurrence of different risk factors with multifactorial analyses, but also by trials investigating the effects of adrenalectomy in ameliorating the metabolic abnormalities $(23,26)$. Nevertheless, despite it being able to play an independent and significant role, cortisol should be considered as an additional player in the set of factors potentially contributing to the development of metabolic alterations. Beside age and being overweight or obese, other important contributors should be taken into account, such as family history of T2D, physical activity and quantity and quality of daily food intake, the effects of all of which are frequently underestimated in studies analyzing patients with SH. Finally, the different duration of cortisol exposure must be also considered. As discussed in the next chapter of this review, retrospective studies analyzing the natural history of this pathological condition have highlighted that the time of exposure to mild cortisol hyperproduction could be an important factor for the development of cardiovascular and metabolic co-morbidities in patients with $\mathrm{SH}$.

\section{SH and clinically-relevant outcomes}

The association between SH and clinically relevant outcomes has attracted the interest of several research groups, and increasing knowledge on this topic has been gained in the last few years. This section of the review will be focused on three clinical outcomes: osteoporotic fractures, cardiovascular diseases, and mortality.

\section{Osteoporotic fractures}

The deleterious effects of glucocorticoids on bone quality are well known from the analysis performed on patients with exogenous and endogenous hypercortisolism. Glucocorticoid-induced osteoporosis (GIO) is a complex disease characterized by increased bone resorption and decreased bone formation. One of the most frequent complications of GIO is the increased rate of vertebral fractures (30). In patients with overt Cushing's syndrome, the reduced bone mineral density and the increased rate of osteoporotic fractures are a frequent complication of untreated hypercortisolism, independently of the underlying mechanism of increased cortisol production. However, several reports have highlighted that impairment of bone metabolism and its clinical consequences can also occur in conditions of mild cortisol excess. The relationship between $\mathrm{SH}$ and clinically relevant outcomes such as vertebral fractures has been intensively investigated over the last 10 years. Indeed, several studies highlighted an increased prevalence of osteoporotic fractures in patients with $\mathrm{SH}$ in comparison to those with non-functioning adrenal masses or control subjects $(31,32,33,34,35,36)$. Fractures were mainly observed in trabecular bone, as expected in GIO, at the level of thoracic spine. The multifactorial analysis performed in the studies cited above shed light on the association between hypercortisolism and alteration of bone microarchitecture (assessed by the spinal deformity index) and increased prevalence of vertebral fractures, which was independent of other known potential contributing factors $(31,32,33,34,36)$. Interestingly, in the paper published by Tauchmanová et al. (32), the prevalence of vertebral fractures in $\mathrm{SH}$ was comparable to that of patients with overt Cushing's syndrome.

Further interesting clues on this topic come from the first longitudinal study investigating the incidence of vertebral fractures in patients with $\mathrm{SH}$. In their cohort of 103 patients followed-up for 2 years, Morelli et al. (35) demonstrated an increased incidence of vertebral fractures in patients with $\mathrm{SH}$ when compared to those with nonfunctioning adrenocortical adenomas (48\% vs $13 \%$ respectively). The risk of developing new fractures was independently associated with the presence of $\mathrm{SH}$ (odds ratio (OR) $12.3,95 \% \mathrm{CI} 4.1-36.5, P=0.001$ ), leading to the 
hypothesis that the higher cortisol production rate detected in these patients could be indeed a causative factor for the increased vertebral fracture rate.

Except for the increased prevalence and incidence of vertebral fractures and the independent association of this outcome with cortisol, some aspects of these manuscripts deserve further reflection. Hypercortisolism has been shown to have the same deleterious effects on bone metabolism in both sexes, since it has previously demonstrated a similar prevalence of vertebral fractures in males (73\% in ref. (33) and 69\% in ref. (34)) and in females (76\% in ref. (34) and 79\% in ref. (31)). Therefore, $\mathrm{SH}$ seems to be a relevant problem for bone quality independently of the sex of patients with adrenal incidentalomas. Another aspect that deserves further discussion is the relationship between cortisol, androgens and osteoporotic fractures. In their paper, Tauchmanová et al. (32) found an independent association between vertebral fractures and the cortisol/DHEAs ratio. The increased cortisol/DHEAs ratio is a well-known characteristic of patients with hypercortisolism and several hypotheses have been proposed to explain this peculiarity.

Molecular in vitro studies have shown that hyperfunctioning adrenocortical cells of adenomas associated with Cushing's syndrome have a low 17,20 lyase activity of the P450c17 enzyme due to a reduced expression of the co-factors cytochrome $b_{5}$ and P450-oxidoreductase (37). Moreover, reduction/suppression of ACTH driven by increased cortisol secretion by the adrenocortical adenoma can decrease the stimulation of the adjacent and contralateral adrenal cortex, resulting in low androgen production. The discovery of the inverse relationship between cortisol and DHEAs levels in hypercortisolism has also led to the proposal in the American guidelines to consider the reduced levels of DHEAs as a possible marker to identify $\mathrm{SH}(11,13)$. Albeit the association between cortisol/DHEAs ratio and vertebral fractures could be due to the major effect of cortisol, it is not negligible that reduced DHEAs (and DHEA) levels could be an important contributing factor. In fact, several population-based longitudinal studies showed an association between DHEAs (and DHEA) and impairment of bone quality (38, 39). However, some reports have been inconclusive in finding any significant association between DHEAs levels and bone quality $(40,41)$. More data in support of the relationship between DHEA and bone quality come from randomized controlled trials showing that DHEA replacement therapy can improve significantly the bone mass density in post-menopausal women $(42,43)$. On the other hand, it must be specified that the beneficial effects of
DHEA replacement in men were not always reproducible, and that the incidence of vertebral fractures has not been investigated in these studies. The exact mechanisms underlying the positive effects of DHEA on bone metabolism remain only speculative; increase in serum testosterone and insulin-like growth factor 1 has been proposed as potential causative factors.

In summary, patients with $\mathrm{SH}$ have an increased prevalence of osteoporotic fractures, but also a significant incidence of developing new fractures, which occur mainly in the thoracic spine. Hypercortisolism, even if mild, has been shown to be an important factor associated with the increased risk of developing such a clinically relevant outcome, acting through mechanisms that seem to be independent (and addictive) to the already known risk factors. The reduction in DHEAs and DHEA levels observed in SH could be also relevant in the impairment of bone quality, even if the contribution of these hormones to the genesis of osteoporotic fractures should be investigated in more detail.

\section{Cardiovascular diseases}

As discussed above, several reports on the co-morbidities associated with $\mathrm{SH}$ have led to the conclusion that the cardiovascular profile is indeed altered in those patients. However, the implications of the subclinical cortisol hypersecretion on the cardiovascular system, in terms of clinically relevant outcomes, have remained elusive until recently.

The first study investigating cardiovascular diseases in SH was published in 2002 (44). In their analysis of 28 patients with SH, Tauchmanová et al. (32) reported a $21 \%$ prevalence of symptomatic cardiovascular diseases and clinical evidence of cardiovascular profile impairment (symptoms of cardiopathy, obstructive vascular disease, carotid atherosclerotic plaques, or electrocardiogram abnormalities suggestive for heart function impairment) in $64 \%$ of the patients. However, no additional analyses were performed to assess the role of cortisol in the development of the impaired cardiovascular profile.

One of the first pieces of evidence for an association between $\mathrm{SH}$ and cardiovascular correlates came from a cross-sectional study published in 2012 (36). In this cohort of 348 patients with adrenal incidentalomas, patients were divided into four subgroups according to their secreting pattern. The progressively increased cortisol hypersecretion was identified by a double cut-off for cortisol levels after DST (below $1.8 \mu \mathrm{g} / \mathrm{dl}$ and above $5 \mu \mathrm{g} / \mathrm{dl}$ to identify non-secreting adenomas and $\mathrm{SH}$ respectively) and by 
additional hormonal parameters in patients with cortisol values between 1.8 and $5 \mu \mathrm{g} / \mathrm{dl}$ (defined as intermediate phenotype). A significant and progressive increase of prevalence of myocardial infarction was observed among groups $(2.9 \%$ in non-secreting, $11.9 \%$ in patients with intermediate phenotype and $26.3 \%$ in $\mathrm{SH}$ ), whereas the prevalence of stroke was not relevant, probably due to the low number of patients. The prevalence of coronary heart disease was associated with intermediate phenotype pattern (OR 4.1, 95\% CI 1.5-11.4, $P=0.007)$ and with $\mathrm{SH}$ (OR 6.1, 95\% CI 1.4-26.5, $P=0.016$ ). Both patterns of secretion were associated with cardiovascular diseases independently of other known risk factors analyzed. Despite the limitations related to the cross-sectional design of the study, which do not allow any causative association, this study provided novel and interesting information that was later confirmed and extended in a subsequent longitudinal study published in 2014 (45). In this retrospective study, 198 patients with adrenal incidentalomas where classified as stable non-secreting and stable $\mathrm{SH}$ according to the cortisol levels after DST (with cut-off of $1.8 \mu \mathrm{g} / \mathrm{dl}$ ) at the first and last evaluation. A subgroup of patients with increasing cortisol levels over time was also identified (worsening group). During a mean follow-up of $7.5 \pm 3.2$ years, patients with $\mathrm{SH}$ and with worsening cortisol secretion showed a higher incidence of cardiovascular disease than those with non-secreting incidentalomas. The higher rate of cardiovascular events was associated with increasing levels of cortisol during followup (Hazard ratio (HR) 1.1, 95\% CI 1.1-1.2, $P=0.001$ ) independent of other known risk factors. Additional interesting results come also from an Italian multicentric study, also published in the beginning of 2014 (46). In this retrospective cohort of 206 patients, $\mathrm{SH}$ was defined by cortisol levels after DST above $5 \mu \mathrm{g} / \mathrm{dl}$, or by at least two hormonal impaired tests, including cortisol after DST above $3 \mu \mathrm{g} / \mathrm{dl}$ ). During a long-term follow-up (median 6 years), Morelli and colleagues found a higher incidence of cardiovascular events in patients with $\mathrm{SH}$ than in those with non-secreting adenomas. The increased rate of cardiovascular events was associated with the presence of SH (OR 3.1, 95\% CI 1.1-9.0, $P<0.05)$. Similar results were also confirmed lately in a retrospective study published by Debono et al. (47) (discussed in detail in the next chapter of this review).

All together, these results highlight some important aspects. First of all, they provide good evidence for a central role of cortisol as a contributing factor to cardiovascular diseases. The deleterious effects of cortisol on the cardiovascular system are an established complication of Cushing's syndrome $(21,22)$, leading to clinically relevant cardiovascular diseases. It is prudent to suspect that the same mechanisms occur also in patients with SH. Despite the specific mechanisms that lead to cardiovascular diseases in subclinical and overt hypercortisolism could share a common basis, it must be considered that this pathological condition is characterized by mild levels of cortisol that persist over a long period of time. Therefore, the impact of the duration of cortisol exposure of the cardiovascular system could be very important in patients with SH, albeit very difficult to demonstrate. The second aspect that deserves attention is that the increased cardiovascular disease rate also occurs in patients with progressive cortisol secretion, highlighting the importance and the necessity of a careful follow-up also in patients with non-secreting adrenocortical adenomas. However, it must be pointed out that not all patients with $\mathrm{SH}$ are at risk of developing cardiovascular diseases. The multifactorial analyses described above highlighted also the independent contribution of other factors besides cortisol that can be useful in drawing a picture of patients potentially at a higher risk for cardiovascular diseases (45). Undoubtedly, further research is needed in this field to try to characterize phenotypical and hormonal features that will help in identifying high-risk patients that could benefit either of surgical treatment, if feasible, or intensive medical therapy of co-morbidities, in order to restrict a careful and intensive follow-up only to patients at risk for clinically relevant outcomes.

\section{Mortality}

The analysis of mortality in patients with adrenal incidentalomas has firstly been described in two old studies, both performed in a long-term follow-up setting (mean 7 years) $(48,49)$. However, no hormonal assessment was addressed to identify patients with $\mathrm{SH}$; therefore, it is difficult to draw definitive conclusions on mortality from the results of these reports. More consistent results were presented in one of the long-term follow-up studies previously cited (45). During a mean 7.5-years follow-up, patients with $\mathrm{SH}$ and with worsened secreting pattern showed a lower survival rate than that of patients with non-secreting adenomas, for all-cause mortality. A sub analysis focused on the cardiovascular-specific mortality confirmed the same trend, with 78.4 and $60 \%$ survival rates for the first two groups respectively and $97.5 \%$ for the latter. Multifactorial analysis confirmed an independent role of cortisol levels after DST in the all-cause mortality (HR 1.1, 95\% CI 1.1-1.2, $P=0.04$ ). 
Debono et al. (47) also presented similar results in a retrospective study published at the end of 2014. In their cohort of 206 patients (mean follow-up $4.2 \pm 2.3$ years), patients with SH defined by cortisol levels after DST above $1.8 \mu \mathrm{g} / \mathrm{dl}$ showed an increased cardiovascular morbidity and mortality than in those with non-secreting adenomas. Interestingly, patients with adrenal incidentalomas showed an increased mortality rate due to cardiovascular diseases and infectious complications when compared to data extracted from the UK population.

Despite the inherent limitations due to the retrospective design and to the low number of deaths of the total cohort of patients, both studies highlight a possible link between SH and mortality of patients with adrenal incidentalomas. Considering that the main cause of mortality was due to cardiovascular diseases and infectious complication, it is feasible that the cortisol can play a significant role.

\section{Future perspectives}

Certainly, the pathological alterations described in this review do not apply to all patients with SH. Further research is therefore needed to identify a subpopulation of subjects at high risk of developing metabolic and cardiovascular abnormalities. In this context, the use of more accurate diagnostic procedures like steroid profiling analysis in blood and urine with gas chromatography/ mass spectrometry (GC/MS) or liquid chromatography/ mass spectrometry (LC/MS) will have the potential to explore glucocorticoid, mineralocorticoid and androgen secretion in an extended quantitative and qualitative way. These innovative assays will have the potential to improve the classification of patients with adrenocortical masses by identifying steroid precursors potentially related to clinical correlates. As an important example of this application, a very recent paper published by Brossaud et al. (50) has provided, for the first time, important clues on the usefulness of urinary steroid profiling with GC/MS in improving the precision of the functional diagnosis of adrenal incidentalomas. Finally, further studies are also needed to understand the optimal treatment for patients with $\mathrm{SH}$, according to their secreting pattern and to the related co-morbidities. To date, there are three ongoing trials investigating the outcome of surgery vs medical treatment in a randomized-controlled setting (available at https://www.clinicaltrials.gov/). Among these, a randomized-controlled trial has been recently designed on a Europe-wide basis in the context of the European Network for the Study of the Adrenal Tumors (ENS@T): Surgery of Subclinical Cortisol Secreting Adrenal Incidentalomas
(CHIRACIC) (trial registration number NCT02364089). The results of this trial, together with the others, are expected to provide extremely useful information on the pathogenetic link between cortisol and cardiovascular diseases, which will help in the identification of a subgroup of patients with $\mathrm{SH}$ who will benefit from surgical treatment.

\section{Conclusion}

Considering all the data reviewed above, it is clear that patients with SH have an increased rate of co-morbidities, such as hypertension, impaired glucose metabolism and increased visceral fat. Albeit the cause-effect relationship with cortisol hypersecretion is difficult to clearly highlight due to the cross-sectional design of the majority of the studies, patients with $\mathrm{SH}$ are at an increased cardiovascular risk with respect to their non-functioning counterparts. Consequently, patients with $\mathrm{SH}$ are more prone to incur cardiovascular diseases and related mortality in a longterm run. In this context, cortisol per se seems to be an important determining factor. Considering that those patients are exposed to mild cortisol levels for a long period, mainly because of the incidental diagnosis and the observational follow-up strategy performed in several centers, a better characterization of the patients is highly needed in order to identify those who can benefit from surgical treatment vs intensive medical therapy of co-morbidities. In conclusion, in the author's opinion, SH should be considered a disease with serious implications on the metabolic and cardiovascular systems.

Declaration of interest

The authors declare that there is no conflict of interest that could be perceived as prejudicing the impartiality of this review.

\section{Funding}

$M$ Reincke is supported by a grant of the Else Kröner-Fresenius Stiftung (2012_A103) in support of the German Cushing's registry (CUSTODES).

\footnotetext{
Acknowledgements

This paper forms part of a special issue of European Journal of Endocrinology on Cushing's syndrome. This article is adapted from work presented at the IMPROCUSH-1: Improving Outcome of Cushing's Syndrome symposium, 12-14 October 2014. The meeting was supported by the European Science Foundation, Deutsche Forschungsgemeinschaft, Carl Friedrich von Siemens Stiftung, European Neuroendocrine Association and the Deutsche Gesellschaft für Endokrinologie. The opinions or views expressed in this article are those of the authors, and do not necessarily reflect the opinions or recommendations of the European Science
} 
Foundation, Deutsche Forschungsgemeinschaft, Carl Friedrich von Siemens Stiftung, European Neuroendocrine Association and the Deutsche Gesellschaft für Endokrinologie

\section{References}

1 Mantero F, Terzolo M, Arnaldi G, Osella G, Masini AM, Alì A, Giovagnetti M, Opocher G \& Angeli A. A survey on adrenal incidentaloma in Italy. Study Group on Adrenal Tumors of the Italian Society of Endocrinology. Journal of Clinical Endocrinology and Metabolism 200085 637-644. (doi:10.1210/jcem.85.2.6372)

2 Terzolo M, Pia A, Alì A, Osella G, Reimondo G, Bovio S, Daffara F, Procopio M, Paccotti P, Borretta G et al. Adrenal incidentaloma: a new cause of the metabolic syndrome? Journal of Clinical Endocrinology and Metabolism 200287 998-1003. (doi:10.1210/jcem.87.3.8277)

3 Chiodini I. Clinical review: diagnosis and treatment of subclinical hypercortisolism. Journal of Clinical Endocrinology and Metabolism 2011 96 1223-1236. (doi:10.1210/jc.2010-2722)

4 Ilias I, Sahdev A, Reznek RH, Grossman AB \& Pacak K. The optimal imaging of adrenal tumours: a comparison of different methods. Endocrine-Related Cancer 2007 14 587-599. (doi:10.1677/ERC-07-0045)

5 Hennings J, Hellman P, Ahlström H \& Sundin A. Computed tomography, magnetic resonance imaging and 11C-metomidate positron emission tomography for evaluation of adrenal incidentalomas. European Journal of Radiology 200969 314-323. (doi:10.1016/ j.ejrad.2007.10.024)

6 Blake MA, Cronin CG \& Boland GW. Adrenal imaging. AJR. American Journal of Roentgenology 2010194 1450-1460. (doi:10.2214/AJR.10.4547)

7 Olsen H, Nordenström E, Bergenfelz A, Nyman U, Valdemarsson S \& Palmqvist E. Subclinical hypercortisolism and CT appearance in adrenal incidentalomas: a multicenter study from Southern Sweden. Endocrine 201242 164-173. (doi:10.1007/s12020-012-9622-2)

8 Kohara K. Sarcopenic obesity in aging population: current status and future directions for research. Endocrine 2014 45 15-25. (doi:10.1007/ s12020-013-9992-0)

9 Schneider HJ, Dimopoulou C, Stalla GK, Reincke M \& Schopohl J. Discriminatory value of signs and symptoms in Cushing's syndrome revisited: what has changed in 30 years? Clinical Endocrinology $2013 \mathbf{7 8}$ 153-154. (doi:10.1111/j.1365-2265.2012.04488.x)

10 NIH state-of-the-science statement on management of the clinically inapparent adrenal mass ("incidentaloma"). NIH Consensus and State-of-the-Science Statements 200219 1-25.

11 Nieman LK, Biller BM, Findling JW, Newell-Price J, Savage MO, Stewart PM \& Montori VM. The diagnosis of Cushing's syndrome: an Endocrine Society Clinical Practice Guideline. Journal of Clinical Endocrinology and Metabolism 200893 1526-1540. (doi:10.1210/ jc.2008-0125)

12 Tabarin A, Bardet S, Bertherat J, Dupas B, Chabre O, Hamoir E, Laurent F, Tenenbaum F, Cazalda M, Lefebvre H et al. French Society of Endocrinology Consensus. Exploration and management of adrenal incidentalomas. French Society of Endocrinology Consensus. Annales d'Endocrinologie 200869 487-500. (doi:10.1016/j.ando.2008.09.003)

13 Zeiger MA, Thompson GB, Duh QY, Hamrahian AH, Angelos P, Elaraj D, Fishman E \& Kharlip J. American Association of Clinical Endocrinologists; American Association of Endocrine Surgeons. The American Association of Clinical Endocrinologists and American Association of Endocrine Surgeons medical guidelines for the management of adrenal incidentalomas. Endocrine Practice 200915 (Suppl 1) 1-20. (doi:10.4158/EP.15.S1.1)

14 Terzolo M, Stigliano A, Chiodini I, Loli P, Furlani L, Arnaldi G, Reimondo G, Pia A, Toscano V, Zini M et al. Italian Association of Clinical Endocrinologists. AME position statement on adrenal incidentaloma. European Journal Endocrinology 2011164 851-870. (doi:10.1530/EJE-10-1147)
15 Shen J, Sun M, Zhou B \& Yan J. Nonconformity in the clinical practice guidelines for subclinical Cushing's syndrome: which guidelines are trustworthy? European Journal Endocrinology 2014171 421-431. (doi:10.1530/EJE-14-0345)

16 Morelli V, Masserini B, Salcuni AS, Eller-Vainicher C, Savoca C, Viti R, Coletti F, Guglielmi G, Battista C, Iorio L et al. Subclinical hypercortisolism: correlation between biochemical diagnostic criteria and clinical aspects. Clinical Endocrinology 201073 161-166. (doi:10.1111/j.13652265.2010.03794.x)

17 Piaditis GP, Kaltsas GA, Androulakis II, Gouli A, Makras P, Papadogias D, Dimitriou K, Ragkou D, Markou A, Vamvakidis K et al. High prevalence of autonomous cortisol and aldosterone secretion from adrenal adenomas. Clinical Endocrinology 200971 772-778. (doi:10.1111/j.1365-2265.2009.03551.x)

18 Androulakis II, Kaltsas G, Piaditis G \& Grossman AB. The clinical significance of adrenal incidentalomas. European Journal of Clinical Investigation 201141 552-560. (doi:10.1111/j.13652362.2010.02436.x)

19 Rizzoni D, Porteri E, De Ciuceis C, Rodella LF, Paiardi S, Rizzardi N, Platto C, Boari GE, Pilu A, Tiberio GA et al. Hypertrophic remodeling of subcutaneous small resistance arteries in patients with Cushing's syndrome. Journal of Clinical Endocrinology and Metabolism 200994 5010-5018. (doi:10.1210/jc.2009-1588)

20 Mihailidou AS, Loan Le TY, Mardini M \& Funder JW. Glucocorticoids activate cardiac mineralocorticoid receptors during experimental myocardial infarction. Hypertension 200954 1306-1312. (doi:10.1161/ HYPERTENSIONAHA.109.136242)

21 De Leo M, Pivonello R, Auriemma RS, Cozzolino A, Vitale P, Simeoli C, De Martino MC, Lombardi G \& Colao A. Cardiovascular disease in Cushing's syndrome: heart versus vasculature. Neuroendocrinology 2010 92 (Suppl 1) 50-54. (doi:10.1159/000318566)

22 Anagnostis P, Athyros VG, Tziomalos K, Karagiannis A \& Mikhailidis DP. Clinical review: the pathogenetic role of cortisol in the metabolic syndrome: a hypothesis. Journal of Clinical Endocrinology and Metabolism 200994 2692-2701. (doi:10.1210/jc.2009-0370)

23 Iacobone M, Citton M, Scarpa M, Viel G, Boscaro M \& Nitti D. Systematic review of surgical treatment of subclinical Cushing's syndrome. British Journal of Surgery 2015 102 318-330. (doi:10.1002/bjs.9742)

24 Ivović M, Marina LV, Vujović S, Tančić-Gajić M, Stojanović M, Radonjić NV, Gajić M, Soldatović I \& Micić D. Nondiabetic patients with either subclinical Cushing's or nonfunctional adrenal incidentalomas have lower insulin sensitivity than healthy controls: clinical implications. Metabolism 201362 786-792. (doi:10.1016/ j.metabol.2012.12.006)

25 Androulakis II, Kaltsas GA, Kollias GE, Markou AC, Gouli AK, Thomas DA, Alexandraki KI, Papamichael CM, Hadjidakis DJ \& Piaditis GP. Patients with apparently nonfunctioning adrenal incidentalomas may be at increased cardiovascular risk due to excessive cortisol secretion. Journal of Clinical Endocrinology and Metabolism 201499 2754-2762. (doi:10.1210/jc.2013-4064)

26 Giordano R, Guaraldi F, Berardelli R, Karamouzis I, D’Angelo V, Marinazzo E, Picu A, Ghigo E \& Arvat E. Glucose metabolism in patients with subclinical Cushing's syndrome. Endocrine 201241 415-423. (doi:10.1007/s12020-012-9628-9)

27 Debono M, Prema A, Hughes TJ, Bull M, Ross RJ \& Newell-Price J. Visceral fat accumulation and postdexamethasone serum cortisol levels in patients with adrenal incidentaloma. Journal of Clinical Endocrinology and Metabolism 201398 2383-2391. (doi:10.1210/jc.2012-4276)

28 Papanastasiou L, Pappa T, Samara C, Apostolopoulou G, Tsiavos V, Markou A, Alexandraki K, Piaditis G, Chrousos G \& Kaltsas G. Nonalcoholic fatty liver disease in subjects with adrenal incidentaloma. European Journal of Clinical Investigation 201242 1165-1172. (doi:10.1111/j.1365-2362.2012.02707.x)

29 Masserini B, Morelli V, Palmieri S, Eller-Vainicher C, Zhukouskaya V, Cairoli E, Orsi E, Beck-Peccoz P, Spada A \& Chiodini I. Lipid abnormalities in patients with adrenal incidentalomas: role of 
subclinical hypercortisolism and impaired glucose metabolism. Journal of Endocrinological Investigation 201538 623-628. (doi:10.1007/ s40618-014-0232-0)

30 Tóth M \& Grossman A. Glucocorticoid-induced osteoporosis: lessons from Cushing's syndrome. Clinical Endocrinology 201379 1-11. (doi:10.1111/cen.12189)

31 Chiodini I, Guglielmi G, Battista C, Carnevale V, Torlontano M, Cammisa M, Trischitta V \& Scillitani A. Spinal volumetric bone mineral density and vertebral fractures in female patients with adrenal incidentalomas: the effects of subclinical hypercortisolism and gonadal status. Journal of Clinical Endocrinology and Metabolism 200489 22372241. (doi:10.1210/jc.2003-031413)

32 Tauchmanovà L, Pivonello R, De Martino MC, Rusciano A, De Leo M, Ruosi C, Mainolfi C, Lombardi G, Salvatore M \& Colao A. Effects of sex steroids on bone in women with subclinical or overt endogenous hypercortisolism. European Journal Endocrinology 2007157 359-366. (doi:10.1530/EJE-07-0137)

33 Chiodini I, Viti R, Coletti F, Guglielmi G, Battista C, Ermetici F, Morelli V, Salcuni A, Carnevale V, Urbano F et al. Eugonadal male patients with adrenal incidentalomas and subclinical hypercortisolism have increased rate of vertebral fractures. Clinical Endocrinology 200970 208-213. (doi:10.1111/j.1365-2265. 2008.03310.x)

34 Chiodini I, Morelli V, Masserini B, Salcuni AS, Eller-Vainicher C, Viti R, Coletti F, Guglielmi G, Battista C, Carnevale V et al. Bone mineral density, prevalence of vertebral fractures, and bone quality in patients with adrenal incidentalomas with and without subclinical hypercortisolism: an Italian multicenter study. Journal of Clinical Endocrinology and Metabolism 200994 3207-3214. (doi:10.1210/jc.2009-0468)

35 Morelli V, Eller-Vainicher C, Salcuni AS, Coletti F, Iorio L, Muscogiuri G, Della Casa S, Arosio M, Ambrosi B, Beck-Peccoz P et al. Risk of new vertebral fractures in patients with adrenal incidentaloma with and without subclinical hypercortisolism: a multicenter longitudinal study. Journal of Bone and Mineral Research 201126 1816-1821. (doi:10.1002/jbmr.398)

36 Di Dalmazi G, Vicennati V, Rinaldi E, Morselli-Labate AM, Giampalma E, Mosconi C, Pagotto U \& Pasquali R. Progressively increased patterns of subclinical cortisol hypersecretion in adrenal incidentalomas differently predict major metabolic and cardiovascular outcomes: a large cross-sectional study. European Journal Endocrinology 2012166 669-677. (doi:10.1530/EJE-11-1039)

37 Miller WL \& Auchus RJ. The molecular biology, biochemistry, and physiology of human steroidogenesis and its disorders. Endocrine Reviews 201132 81-151. (doi:10.1210/er.2010-0013)

38 Ghebre MA, Hart DJ, Hakim AJ, Kato BS, Thompson V, Arden NK, Spector TD \& Zhai G. Association between DHEAS and bone loss in postmenopausal women: a 15-year longitudinal population-based study. Calcified Tissue International 201189 295-302. (doi:10.1007/ s00223-011-9518-9)

39 Garnero P, Sornay-Rendu E, Claustrat B \& Delmas PD. Biochemical markers of bone turnover, endogenous hormones and the risk of fractures in postmenopausal women: the OFELY study. Journal of Bone and Mineral Research 200015 1526-1536. (doi:10.1359/jbmr.2000.15.8.1526)

40 Zofková I, Bahbouh R \& Hill M. The pathophysiological implications of circulating androgens on bone mineral density in a normal female population. Steroids 200065 857-861. (doi:10.1016/S0039128X(00)00136-7)

41 Guthrie JR, Lehert P, Dennerstein L, Burger HG, Ebeling PR \& Wark JD. The relative effect of endogenous estradiol and androgens on menopausal bone loss: a longitudinal study. Osteoporosis International 200415 881-886. (doi:10.1007/s00198-004-1624-3)

42 Baulieu EE, Thomas G, Legrain S, Lahlou N, Roger M, Debuire B, Faucounau V, Girard L, Hervy MP, Latour F et al. Dehydroepiandrosterone (DHEA) DHEA sulfate, and aging: contribution of the DHEAge Study to a sociobiomedical issue. PNAS 200097 4279-4284. (doi:10.1073/pnas.97.8.4279)
43 Nair KS, Rizza RA, O'Brien P, Dhatariya K, Short KR, Nehra A, Vittone JL, Klee GG, Basu A, Basu R et al. DHEA in elderly women and DHEA or testosterone in elderly men. New England Journal of Medicine 2006355 1647-1659. (doi:10.1056/NEJMoa054629)

44 Tauchmanovà L, Rossi R, Biondi B, Pulcrano M, Nuzzo V, Palmieri EA, Fazio S \& Lombardi G. Patients with subclinical Cushing's syndrome due to adrenal adenoma have increased cardiovascular risk. Journal of Clinical Endocrinology and Metabolism 200287 4872-4878. (doi:10.1210/ jc.2001-011766)

45 Di Dalmazi G, Vicennati V, Garelli S, Casadio E, Rinaldi E, Giampalma E, Mosconi C, Golfieri R, Paccapelo A, Pagotto U et al. Cardiovascular events and mortality in patients with adrenal incidentalomas that are either non-secreting or associated with intermediate phenotype or subclinical Cushing's syndrome: a 15-year retrospective study. Lancet. Diabetes \& Endocrinology 20142 396-405. (doi:10.1016/ S2213-8587(13)70211-0)

46 Morelli V, Reimondo G, Giordano R, Della Casa S, Policola C, Palmieri S, Salcuni AS, Dolci A, Mendola M, Arosio M et al. Long-term follow-up in adrenal incidentalomas: an Italian multicenter study. Journal of Clinical Endocrinology and Metabolism 201499 827-834. (doi:10.1210/jc.2013-3527)

47 Debono M, Bradburn M, Bull M, Harrison B, Ross RJ \& Newell-Price J. Cortisol as a marker for increased mortality in patients with incidental adrenocortical adenomas. Journal of Clinical Endocrinology and Metabolism 201499 4462-4470. (doi:10.1210/jc.2014-3007)

48 Barry MK, van Heerden JA, Farely DR, Grant CS, Thompson GB \& Ilstrup DM. Can adrenal incidentalomas be safely observed? World Journal of Surgery 199822 599-604. (doi:10.1007/s002689900441)

49 Sirén J, Tervahartiala P, Sivula A \& Haapiainen R. Natural course of adrenal incidentalomas: seven-year follow-up study. World Journal of Surgery 200024 579-582. (doi:10.1007/s002689910095)

50 Brossaud J, Ducint D \& Corcuff JB. Urinary glucocorticoid metabolites: biomarkers to classify adrenal incidentalomas? Clinical Endocrinology 2015. In press. (doi:10.1111/cen.12717)

51 Rossi R, Tauchmanova L, Luciano A, Di Martino M, Battista C, Del Viscovo L, Nuzzo V \& Lombardi G. Subclinical Cushing's syndrome in patients with adrenal incidentaloma: clinical and biochemical features. Journal of Clinical Endocrinology and Metabolism 200085 1440-1448. (doi:10.1210/jcem.85.4.6515)

52 Terzolo M, Bovio S, Pia A, Conton PA, Reimondo G, Dall'Asta C, Bemporad D, Angeli A, Opocher G, Mannelli M et al. Midnight serum cortisol as a marker of increased cardiovascular risk in patients with a clinically inapparent adrenal adenoma. European Journal Endocrinology 2005153 307-315. (doi:10.1530/eje.1.01959)

53 Erbil Y, Ademoğlu E, Ozbey N, Barbaros U, Yanik BT, Salmaslioğlu A, Bozbora A \& Ozarmağan S. Evaluation of the cardiovascular risk in patients with subclinical Cushing syndrome before and after surgery. World Journal of Surgery 200630 1665-1671. (doi:10.1007/s00268-0050681-x)

54 Masserini B, Morelli V, Bergamaschi S, Ermetici F, Eller-Vainicher C, Barbieri AM, Maffini MA, Scillitani A, Ambrosi B, Beck-Peccoz P et al. The limited role of midnight salivary cortisol levels in the diagnosis of subclinical hypercortisolism in patients with adrenal incidentaloma. European Journal Endocrinology 2009160 87-92. (doi:10.1530/EJE08-0485)

55 Toniato A, Merante-Boschin I, Opocher G, Pelizzo MR, Schiavi F \& Ballotta E. Surgical versus conservative management for subclinical Cushing syndrome in adrenal incidentalomas: a prospective randomized study. Annals of Surgery 2009249 388-391. (doi:10.1097/SLA. 0b013e31819a47d2)

56 Vassilatou E, Vryonidou A, Michalopoulou S, Manolis J, Caratzas J, Phenekos C \& Tzavara I. Hormonal activity of adrenal incidentalomas: results from a long-term follow-up study. Clinical Endocrinology $2009 \mathbf{7 0}$ 674-679. (doi:10.1111/j.1365-2265.2008.03492.x)

57 Chiodini I, Morelli V, Salcuni AS, Eller-Vainicher C, Torlontano M, Coletti F, Iorio L, Cuttitta A, Ambrosio A, Vicentini L et al. Beneficial 
metabolic effects of prompt surgical treatment in patients with an adrenal incidentaloma causing biochemical hypercortisolism. Journal of Clinical Endocrinology and Metabolism 201095 2736-2745. (doi:10.1210/jc.2009-2387)

58 Giordano R, Marinazzo E, Berardelli R, Picu A, Maccario M, Ghigo E \& Arvat E. Long-term morphological, hormonal, and clinical follow-up in a single unit on 118 patients with adrenal incidentalomas. European Journal Endocrinology 2010162 779-785. (doi:10.1530/EJE-09-0957)

59 Eller-Vainicher C, Morelli V, Salcuni AS, Battista C, Torlontano M, Coletti F, Iorio L, Cairoli E, Beck-Peccoz P, Arosio M et al. Accuracy of several parameters of hypothalamic-pituitary-adrenal axis activity in predicting before surgery the metabolic effects of the removal of an adrenal incidentaloma. European Journal Endocrinology 2010163 925-935. (doi:10.1530/EJE-10-0602)

60 Alesina PF, Hommeltenberg S, Meier B, Petersenn S, Lahner H, Schmid KW, Mann K \& Walz MK. Posterior retroperitoneoscopic adrenalectomy for clinical and subclinical Cushing's syndrome. World Journal of Surgery 201034 1391-1397. (doi:10.1007/s00268-010-0453-0)

61 Akaza I, Yoshimoto T, Iwashima F, Nakayama C, Doi M, Izumiyama H \& Hirata Y. Clinical outcome of subclinical Cushing's syndrome after surgical and conservative treatment. Hypertension Research 201134 1111-1115. (doi:10.1038/hr.2011.90)

62 Iacobone M, Citton M, Viel G, Boetto R, Bonadio I, Mondi I, Tropea S, Nitti D \& Favia G. Adrenalectomy may improve cardiovascular and metabolic impairment and ameliorate quality of life in patients with adrenal incidentalomas and subclinical Cushing's syndrome. Surgery 2012152 991-997. (doi:10.1016/j.surg.2012.08.054)

63 Morelli V, Palmieri S, Salcuni AS, Eller-Vainicher C, Cairoli E, Zhukouskaya V, Scillitani A, Beck-Peccoz P \& Chiodini I. Bilateral and unilateral adrenal incidentalomas: biochemical and clinical characteristics. European Journal Endocrinology 2013168 235-241. (doi:10.1530/EJE-12-0777)
64 Perysinakis I, Marakaki C, Avlonitis S, Katseli A, Vassilatou E, Papanastasiou L, Piaditis G \& Zografos GN. Laparoscopic adrenalectomy in patients with subclinical Cushing syndrome. Surgical Endoscopy 201327 2145-2148. (doi:10.1007/s00464-012-2730-5)

65 Palmieri S, Morelli V, Polledri E, Fustinoni S, Mercadante R, Olgiati L, Eller Vainicher C, Cairoli E, Zhukouskaya VV \& Beck-Peccoz P. The role of salivary cortisol measured by liquid chromatographytandem mass spectrometry in the diagnosis of subclinical hypercortisolism. European Journal Endocrinology 2013168 289-296. (doi:10.1530/EJE-12-0803)

66 Vassilatou E, Vryonidou A, Ioannidis D, Paschou SA, Panagou M \& Tzavara I. Bilateral adrenal incidentalomas differ from unilateral adrenal incidentalomas in subclinical cortisol hypersecretion but not in potential clinical implications. European Journal Endocrinology 2014 171 37-45. (doi:10.1530/EJE-13-0848)

67 Kawate H, Kohno M, Matsuda M, Akehi Y, Tanabe M, Horiuchi T, Ohnaka K, Nomura M, Yanase T \& Takayanagi R. Long-term study of subclinical Cushing's syndrome shows high prevalence of extraadrenal malignancy in patients with functioning bilateral adrenal tumors. Endocrine Journal 201461 1205-1212. (doi:10.1507/endocrj. EJ14-0155)

68 Kim BY, Chun AR, Kim KJ, Jung CH, Kang SK, Mok JO \& Kim CH. Clinical characteristics and metabolic features of patients with adrenal incidentalomas with or without subclinical Cushing's syndrome. Endocrinology and Metabolism 201429 457-463. (doi:10.3803/EnM. 2014.29.4.457)

69 Ricciato MP, Di Donna V, Perotti G, Pontecorvi A, Bellantone R \& Corsello SM. The role of adrenal scintigraphy in the diagnosis of subclinical Cushing's syndrome and the prediction of post-surgical hypoadrenalism. World Journal of Surgery 201438 1328-1335.

Received 9 March 2015

Revised version received 9 June 2015

Accepted 23 June 2015 